\title{
Técnicas histopatológicas no diagnóstico de criptococose por Cryptococcus deficiente de cápsula: relato de caso
}

\author{
Histopathological techniques for diagnosing cryptococcosis \\ due to capsule-deficient Cryptococcus: case report
}

\author{
Alexandra Flávia Gazzoni ${ }^{1}$, Karla Lais Pegas $^{2}$ e Luiz Carlos Severo ${ }^{3}$
}

\begin{abstract}
RESUMO
Caso de criptococose por Cryptococcus deficiente de cápsula, no qual cultivo do espécime clínico e pesquisa do antígeno capsular no líquor e soro foram negativos. As técnicas histopatológicas foram: Hematoxilina-eosina, Grocott, Mucicarmim de Mayer e Fontana-Masson. Confirmou-se o diagnóstico do Cryptococcus deficiente de cápsula pela técnica de Fontana-Masson e pela imunofluorescência direta. É discutida a potencialidade das técnicas histoquímicas.
\end{abstract}

Palavras-chaves: Cryptococcus deficiente de cápsula. Mucicarmim de Mayer. Fontana-Masson.

\section{ABSTRACT}

A case of cryptococcosis due to capsule-deficient Cryptococcus is presented, in which culturing of the clinical specimen and tests for capsular antigen in cerebrospinal fluid and serum were negative. The histopathological techniques evaluated were hematoxylin-eosin, Grocott methenamine silver, Mayer's mucicarmine and Fontana-Masson. The diagnosis of cryptococcosis due to capsule-deficient Cryptococcus was confirmed by means of the Fontana-Masson technique and by direct immunofluorescence. The potential of the histochemical techniques is discussed.

Key-words: Capsule-deficient Cryptococcus. Mucicarmine. Fontana-Masson.

Acriptococoseéumamicose sistêmicacausadafundamentalmente por duas espécies do basidiomiceto, naturalmente encapsulado Cryptococcus neoformans e Cryptococcus gattii. Enquanto o Cryptococcus neoformans tem distribuição mundial, é sapróbio do solo e está presente em maior abundância em ambientes contaminados pelas fezes de pombos, o Cryptococcus gattii fica praticamente restrito a climas tropicais e subtropicais e está associado a árvores como Eucalyptus camaldulensis ${ }^{2}$.

O estabelecimento do diagnóstico laboratorial da criptococose é feito pelos achados microscópicos (exame direto e histopatologia), isolamento em cultivo e soromicologia, realizada pelo teste de aglutinação das partículas do látex através da detecção do antígeno capsular. As características micromorfológicas do Cryptococcus são elementos esféricos a ovais, com ou sem brotamentos, medindo de 4 a $20 \mu \mathrm{m}$ de diâmetro, envoltos por uma cápsula gelatinosa ${ }^{2}$. Contudo, a literatura registra casos de criptococose sem estas características, dificultando o diagnóstico por simular outros elementos fúngicos ${ }^{1456712131415161718}$, o que demanda uma técnica laboratorial mais específica ${ }^{815}$.

Justifica o relato a avaliação das potencialidades e limitações diagnósticas das técnicas histopatológicas na criptococose.

\section{RELATO DO CASO}

Paciente feminina, de 42 anos, branca, natural e procedente de Guaíba, Rio Grande do Sul. Interna com tosse seca, cefaléia, dor ventilatório-dependente no hemitórax direito e febre. Exame físico sem particularidades. Radiografia do tórax revelou nódulos subpleurais no lobo inferior do pulmão direito. Realizada toracotomia à direita. A macroscopia da peça cirúrgica evidenciou três nódulos subpleurais de aspecto caseoso. Realizada punção liquórica, o exame microbiológico do líquor mostrou ausência de germes aos esfregaços corados; os cultivos para bactérias, micobactérias e fungos obtiveram resultados negativos.

Espécime clínico. Peça cirúrgica de tecido pulmonar macroscopicamente alterado foi submetido a processamento histológico padrão e incluso em blocos de parafina. A seguir, os cortes foram corados por meio de técnicas padronizadas ${ }^{8}$.

Técnicas histoquímicas. Hematoxilina-eosina (HE): rotina no diagnóstico histológico e de grande utilidade na avaliação dos padrões de reações teciduais ${ }^{5}$.

Grocott: também chamada de impregnação pela prata é a mais sensível, sendo largamente utilizada na pesquisa dos

\footnotetext{
1. Curso de Pós-Graduação em Ciências Pneumológicas, Universidade Federal do Rio Grande do Sul, Porto Alegre, RS. 2. Departamento de Patologia, Santa Casa-Complexo Hospitalar, Porto Alegre, RS. 3. Departamento de Medicina Interna, Faculdade de Medicina, Universidade Federal do Rio Grande do Sul, Porto Alegre, RS.

Endereço para correspondência: Dr. Luiz Carlos Severo. Laboratório de Micologia/Santa Casa Complexo Hospitalar. Rua Anne Dias 285, $90020-090$ Porto Alegre, RS Tel: $55513214-8409$

e-mail: severo@santacasa.tche.br

Recebido para publicação em: 10/09/2007

Aceito em: 15/01/2008
} 
elementos fúngicos tanto nos cortes de tecido, quanto nos esfregaços, corando de negro a parede celular, que é visualizada sobre um fundo verde-claro ${ }^{89}$.

Mucicarmim de Mayer: diferencia o Cryptococcus de outros fungos similares em tamanho e forma. Método exclusivo de visualização do material polissacarídico capsular. 0 carmim liga-se a mucina, a qual destaca-se dos outros componentes celulares pela coloração magenta ${ }^{3911}$.

Fontana-Masson: evidencia a parede celular fúngica por reagir com pigmentos de melanina, bem como grânulos argentafins. A melanina corada destaca-se do restante do tecido, que adquire coloração amarelada ${ }^{8911}$.

Imunofluorescência: técnica restrita a único centro de referência, baseada na formação de um conjugado composto por anticorpos fluorescentes específicos e antígenos do polissacarídeo capsular ${ }^{3}$.

Soromicologia. teste de detecção do antígeno polissacarídeo capsular através da aglutinação das partículas de látex sensibilizadas ${ }^{2}$.

A Tabela 1 resume as finalidades e limitações das colorações histoquímicas quando do diagnóstico de criptococose por Cryptococcus deficiente de cápsula.

Posteriormente, houve análise microscópica comparativa entre a técnica de rotina (HE) e três técnicas especiais da micologia.

Aos cortes, os achados microscópicos à coloração de hematoxilina-eosina revelaram lesões granulomatosas, de intensa resposta inflamatória, constituídas por macrófagos, coleções nodulares de células epitelióides (macrófagos modificados que adquirem citoplasma mais pálido, à semelhança das células epiteliais), células gigantes e fagocitose. Alguns linfócitos estavam dispostos perifericamente (Figura 1A). Não foram identificados polimorfonucleares. Alguns organismos esféricos de tamanho varíavel foram identificados no interior dos granulomas (Figura 1B). A coloração de Grocott revelou numerosos organismos dispostos ora dentro de células gigantes (fagocitados), ora no tecido necrótico e espaço extracelular. A parede celular dos elementos fúngicos corou-se de marrom-escuro a preto, sem visualização do espaço claro circundante. Raramente, se observou elementos com brotamento unipolar (Figura 1C). A coloração de mucicarmim de Mayer para estrutura capsular foi fracamente reativa (Figura 1D). A melanina foi evidenciada com a coloração de Fontana-Masson, a qual variou de marrom-escura a negra (Figura 1E). Duas técnicas diagnósticas foram realizadas no CDC (Centers for Disease Control and Prevention), Atlanta, EUA. A pesquisa do antígeno polissacarídico capsular (aglutinação com partículas de látex sensibilizadas) no líquido cefalorraquidiano e no soro que foram negativas. A técnica de imunofluorescência direta, obtendo resultados fracamente reativos para material capsular, confirmando o diagnóstico de Cryptococcus deficiente de cápsula.

Tabela 1 - Finalidades e limitações das técnicas bistopatológicas no diagnóstico da criptococose por Cryptococcus deficiente de cápsula.

\begin{tabular}{lll}
\hline & Finalidades & Limitações \\
\hline HE & reação tecidual & não evidencia as estruturas \\
& fúngicas \\
\hline GMS & cora parede celular dos fungos & complexidade no procedimento \\
& & alto custo \\
\hline MM & cora envelope capsular & insuficiente no diagnóstico de \\
& & Cryptococcus deficientes de cápsula \\
\hline FM & cora melanina na parede celular fúngica & complexidade no procedimento \\
& & alto custo \\
\hline
\end{tabular}

HE: hematoxilina-eosina, GMS: Grocott-methenamine silver, MM: mucicarmim de Mayer, FM: Fontana-Masson.

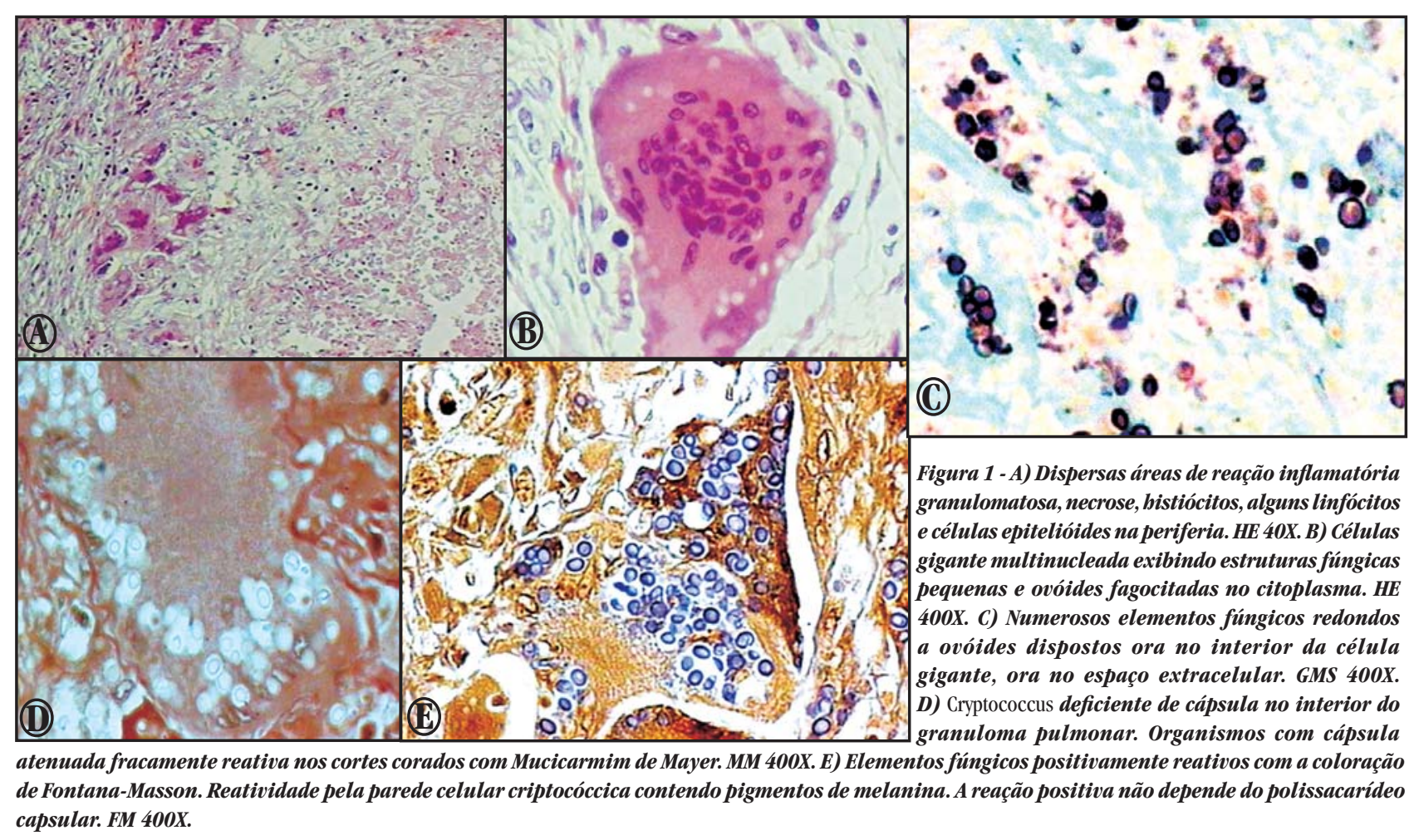




\section{DISCUSSÃo}

A literatura mostra relatos de criptococose pulmonar ${ }^{5} \mathrm{e}$ disseminada ${ }^{14}$ por formas deficientes de cápsula. Em 28 casos revisados, 14 (50\%) pacientes exibiam infecção pulmonar ${ }^{45} 1517$ e os outros 14 (50\%) pacientes apresentavam sinais de doença extrapulmonar: meningite ${ }^{16}$, sepse $\mathrm{e}^{1}$, sepse concomitante com meningite ${ }^{14}$, infecção óssea ${ }^{6}$, prostatite $^{13} \mathrm{e}_{\text {artrite }}{ }^{12}$. 0 diagnóstico histopatológico foi realizado em 17 (61\%) pacientes ${ }^{4567121315}$. A técnica de hematoxilina-eosina foi realizada em 9 (53\%) pacientes 3567121315 , com observação de granuloma, célula gigante e fagocitose em $100 \%$ dos casos, demonstrando que a criptococose ocasionada por formas deficientes de cápsula produz intensa resposta inflamatória. A técnica de Grocott foi realizada em $100 \%$ dos casos ${ }^{4} 56712131517$, foram visualizados aspectos como parede celular e brotamentos compatíveis com Cryptococcus. A técnica de mucicarmim de Mayer também foi realizada em $100 \%$ dos casos ${ }^{4} 56712131517$, sendo negativa em 7 (41\%) pacientes 45671315 ; nos 10 (59\%) casos restantes $^{72} 17$, a técnica obteve resultados levemente positivos. A técnica de Fontana-Masson foi realizada em 6 (35\%) pacientes, sendo reativa em todos os $\operatorname{cas}^{4} \mathrm{~s}^{471315}$. Portanto, esta coloração demonstra-se altamente específica no diagnóstico das formas deficientes de cápsula. A técnica de imunofluorescência foi realizada em 4 (14\%) $\operatorname{casos}^{671216}$. Conforme resultados observados em outra revisão de $39 \operatorname{casos}^{18}$, estruturas fúngicas deficientes de cápsula exibiram reações fracamente positivas para material capsular por esse método. Em adição, a baixa porcentagem deste último, é devido ao fato de que este tipo de procedimento está restrito a um único centro de referência. Como vimos, os achados do presente caso estão em concordância com a literatura.

Por outro lado, a soromicologia baseada na aglutinação das partículas de látex sensibilizadas foi realizada em 22 (79\%) casos $^{15612131617}, 13$ foram aplicados no soro ${ }^{156121317}, 11$ aplicados no líquido cefalorraquidiano ${ }^{1512}$ e 1 aplicado no líquido sinovial $^{12}$. No soro, a negatividade foi em $8(36 \%) \operatorname{casos}^{161217}$ e a positividade em 5 (22\%) $\operatorname{casos}^{1513}$. No líquido cefalorraquidiano, a negatividade em 3 (13\%) $\operatorname{casos}^{512} 16$ e a positividade foi em 8 (36\%) casos $^{1}$. No líquido sinovial, o resultado foi negativo ${ }^{12}$. Este percentual de negatividade, como era de se esperar, é reflexo da deficiência de material capsular.

Em resumo, os achados morfológicos proporcionados pelas colorações de hematoxilina-eosina e Grocott, bem como os resultados oferecidos pelas técnicas histopatológicas de FontanaMasson e mucicarmim de Mayer estabelecem o diagnóstico dos organismos criptocóccicos. Portanto, o Fontana-Masson é alternativa diagnóstica para casos de infecções por organismos morfologicamente sugestivos de Cryptococcus, uma vez que a imunofluorescência direta está disponível somente em um centro de referência.

\section{AGRADECIMENTOS}

Ao Dr. Leo Kaufman pela realização da soromicologia e ao Dr. William Kaplan pela realização da imunofluorescência direta, ambos do Centers for Disease Control and Prevention (CDC), Atlanta, USA.

\section{REFERÊNCIAS}

1. Bottone EJ, Toma M, Johansson BE, Wormser GP. Poorly encapsulated Cryptococcus neoformans from patients with AIDS. I: Preliminary observations. AIDS Research 2: 211-217, 1986.

2. Casadevall A, Perfect JR. Cryptococcus neoformans. The American Society for Microbiology - ASM Press, Washington, 1998.

3. Chandler FW, Watts JC. Cryptococcosis. In: Connor DH, Chandler FW, Schwartz DA, Manz HJ, Lack EE, Baird JK, Utz JP (eds) Pathology of infectious diseases, Appleton \& Lange, Stamford, p. 989-997, 1997.

4. Cheon WS, Eom K, Yoo BK, Jang SH, Bahn JW, Kim DG, Jung KS. A case of pulmonary cryptococcosis by capsule-deficient Cryptococcus neoformans. The Korean Journal of Internal Medicine 21: 83-87, 2006.

5. Harding, SA, Scheld WM, Feldman PS, Sande MA. Pulmonary infection with capsule-deficient Cryptococcus neoformans. Virchows Archives A Pathological Anatomy and Histology 382: 113-118, 1979.

6. Heenan PJ, Dawkins RL. Cryptococcosis and multiple squamous cell tumors associated with a T-cell defect. Cancer 47: 291-295, 1981.

7. Kimura M, Kaufman L, Maekura S, Teramura K, Satou T, Hashimoto S. Pulmonary cryptococcosis due to capsule-deficient strain confused with metastatic lung cancer. Mycopathologia 140: 65-68, 1998.

8. Kwon-Chung KJ, Hill WB, Bennett JE. New, special stain for histopathological diagnosis of cryptococcosis. Journal of Clinical Microbiology 13: 383-387, 1981.

9. Lacaz CS, Porto E, Martins JEC, Heins-Vaccari EM, Melo NT. Tratado de Micologia Médica - Lacaz. Editora Sarvier, São Paulo, 2002.

10. Lazcano O, Speights VO, Strickler JG, Bilbao JE, Becker J, Diaz J. Combined histochemical stains in the differential diagnosis of Cryptococcus neoformans. Modern Pathology 6: 80-84, 1993.

11. Lazcano O, Speights VO Jr, Bilbao J, Becker J, Diaz J. Combined Fontana-MassonMucin staining of Cryptococcus neoformans. Archives of Pathology \& Laboratory Medicine 115: 1145-1149, 1991.

12. Levinson DJ, Silcox DC, Rippon JW, Thomsen S. Septic Arthritis due to nonencapsulated Cryptococcus neoformans with coexisting sarcoidosis. Arthritis and Rheumatism 17: 1037-1047, 1974.

13. Milchgrub S, Visconti E, Avellini J. Granulomatous prostatitis induced by capsuledeficient cryptococcal infection. The Journal of Urology 143: 365-366, 1989.

14. Mukae H, Iwamoto M, Kinoshita A, Takase T, Mori N, Ishino T, Kohno S, Yamaguchi K, Hirota M, Hara K. A case of sepsis and meningitis due to capsule-deficient Cryptococcus neoformans with SIADH. Kansenshogaku Zasshi 63: 1206-1211, 1989.

15. Ro JY, Lee SS, Ayala AG. Advantage of Fontana-Masson stain in capsule-deficient cryptococcal infection. Archives of Pathology \& Laboratory Medicine 111: 53-57, 1987.

16. Sugiura Y, Homma M, Yamamoto T. Difficulty in diagnosing chronic meningitis caused by capsule-deficient Cryptococcus neoformans. Journal of Neurology Neurosurgery and Psychiatry 76: 1460-1461, 2005.

17. Torres HA, Prieto VG, Raad II, Kontoyiannis DP. Proven pulmonary cryptococcosis due to capsule-deficient Cryptococcus neoformans does not differ clinically from proven pulmonary cryptococcosis due to capsule-intact $\mathrm{Cr}$. neoformans. Mycoses 48: 21-24, 2005.

18. Watts JC, Chandler FW. Infection by capsule-deficient cryptococci (letter). Archives of Pathology \& Laboratory Medicine 111: 688-689, 1987. 